\title{
Fabrication and Characterization of Chitosan-Collagen Membrane from Barramundi (Lates Calcarifer) Scales for Guided Tissue Regeneration
}

\author{
Agus Susanto ${ }^{1}$ Mieke Hemiawati Satari ${ }^{2}$ Basril Abbas ${ }^{3}$ \\ Arief Cahyanto ${ }^{4}$ \\ ${ }^{1}$ Department of Periodontics, Faculty of Dentistry, Padjadjaran \\ University, Bandung, Indonesia \\ 2Department of Oral Biology, Faculty of Dentistry, Padjadjaran \\ University, Bandung, Indonesia \\ ${ }^{3}$ National Nuclear Energy Agency of Indonesia (BATAN), Jakarta, \\ Indonesia \\ ${ }^{4}$ Department of Dental Materials Science and Technology, Faculty \\ of Dentistry, Padjadjaran University, Bandung, Indonesia
}

R. Setyo Adji Koesoemowidodo 3

Eur J Dent 2019;13:370-375

\author{
Address for correspondence Agus Susanto, drg. MKes, SpPerio, \\ Department of Periodontics, Faculty of Dentistry, Universitas \\ Padjadjaran, Sekeloa Selatan I, Bandung 40132, Indonesia \\ (e-mail: agus.susanto@fkg.unpad.ac.id).
}

\begin{abstract}
Keywords

- characterization

- chitosan

- collagen

- membrane

- guided tissue

regeneration
\end{abstract}

Objectives The aim of this study was to evaluate the synthesis, mechanical strength, and morphology of chitosan-collagen membranes from barramundi scales for guided tissue regeneration technique.

Materials and Methods Collagen was extracted from barramundi scales by immersion in acetic acid. The resulting wet collagen was later dried. The membrane was fabricated by mixing chitosan with collagen from barramundi scales. Membrane characterization parameters were measured using Fourier transform infrared (FTIR), scanning electron microscopy (SEM) and mechanical property.

Results The FTIR spectrum showed the typical peak of the mixture of chitosan and collagen. The tensile strength and elongation at break of the membrane in dry condition were $0.28 \mathrm{MPa}$ and $8.53 \%$, respectively, while in the wet condition these were $0.12 \mathrm{MPa}$ and $25.6 \%$. The membrane porosity test result was $38.85 \%$; SEM result showed a porous membrane surface with size varying around 16 to $100 \mu \mathrm{m}$.

Conclusion The chitosan-collagen membrane from the barramundi scale showed the fibrous membrane surface that has ideal porous size as guided tissue regeneration membrane and the lower mechanical strength.

\section{Introduction}

The ultimate goal of periodontal therapy is to restore periodontal attachment, including cementum, periodontal ligament, and alveolar bone loss caused by periodontal disease. ${ }^{1}$ Tissue engineering approaches have been introduced as an innovative alternative to conventional biomaterials to replace the lost or damaged human oral tissues. Various studies have attempted to regenerate dental tissues using a variety of scaffold materials such as natural polymers (collagen, polysaccharides, or fibrin). ${ }^{2}$ In dentistry, collagen is used as a membrane for guided tissue regeneration (GTR) or guided bone regeneration (GBR). ${ }^{3}$ Ideal requirements for GTR membranes include occlusive cells that meet minimum mechanical, physical, structural, and biocompatibility requirements; ability to support vascularization and wound stabilization; protect blood clots thereby limiting epithelial connective tissue growth and unwanted into the defect; promote regeneration of functional tissue from cells that are relevant in the defect (avoid healing by repair); and provide space for newly formed periodontal tissues. ${ }^{4,5}$ 
Collagen is the main structural component of connective tissue that covers nearly $30 \%$ of the total protein in the body system. Collagen has been widely used as an essential compound in the food industry, pharmaceuticals, cosmetics, and biomedicals. ${ }^{6}$ GTR or GBR membranes generally originate from collagen derived from the bone raw materials and mammalian skin, such as cattle and pigs. Raw materials from pigs, however, are not justified for Muslims and Jews, while the use of cow bones and skin is restricted for Hindus and raises concerns due to the presence of bovine spongiform encephalopathy or is also known as mad cow disease. ${ }^{7}$ Consumption of bovine collagen allows transmission of infectious diseases toward humans. Therefore, an alternative collagen sourced from fish is currently being developed.

Waste from fisheries processing is known to reach up to $75 \%$ of the total of fish's weight. The wastes are in the form of bones, skin, and fish scales, which are considered as lowvalue materials. ${ }^{8}$ The processing of fisheries waste is expected to be able to reduce the waste volume while providing added value to the products manufactured. ${ }^{9}$ Collagen is one of the materials contained in prospective fisheries waste to be developed. More than $30 \%$ of fishery waste as mentioned above is very rich in collagen, which can become a better alternative source of collagen. Various studies have reported extraction of collagen from Nile perch fish (Lates niloticus) skin, ${ }^{10}$ big eye snapper (Priacanthus tayenus), ${ }^{8}$ and grass carp (Ctenopharyngodon idella). ${ }^{11}$ In addition to fish skin, fish scales also can become a collagen source. In this study, the source of collagen was extracted from white snapper scales. Barramundi is one type of edible portion fish in Indonesia whose wastes can be used as the collagen source. Indonesia as a maritime country has a great potential to develop fish collagen. Collagen from barramundi scales has a more stable collagen structure and is difficult to be degraded, with a porous surface, and is a quite good tensile strength. ${ }^{12,13}$

Other natural ingredients that are often used in the medical field are chitosan. Chitosan is an amino polysaccharide, which has attracted significant scientific interest during the past few decades. It is a partially deacetylated form of chitin, well known for showing biocompatibility, biodegradability, and antimicrobial activity. ${ }^{14,15}$ Chitosan has been processed in various forms used in tissue engineering applications, such as membranes, nanoparticles, gels, scaffold, and sponge structure $^{16,17}$. Previous research of barramundi collagen is used as wound dressing and corneal tissue engineering. To the best of our knowledge, research on membranes sourced from fish collagen is still being conducted and the research is still limited. The purpose of this study was to evaluate the synthesis, mechanical strength, and morphology of chitosan-collagen membranes from barramundi scales for GTR technique.

\section{Materials and Methods}

Materials and tools used for the fabrication of collagen membranes were as follows: the barramundi scales, chitosan (Surindo Co., Jakarta, Indonesia), 100\% acetic acid, potassium bromide, distilled water, ethanol, sodium hydroxide, phosphate buffer saline, homogeneous, petri dish, Fourier transform infrared (FTIR), universal testing machine, and scanning electron microscope (SEM).

\section{Collagen Extraction from Barramundi Scales}

Collagen extraction was performed by immersing the barramundi scales in the acetic acid, as referred to the study of Muyonga et al in 2004. The collagen was extracted using acetic acid solution with a concentration of $0.5 \mathrm{M}$ at $4^{\circ} \mathrm{C}$ for 3 days followed by regular stirring. Extraction was then repeated with the same reagents and conditions and then the obtained filtrate was centrifuged at 10,000 rpm for $30 \mathrm{~min}-$ utes. Collagen precipitation was performed by adding $\mathrm{NaCl}$ to the supernatant with the concentration of $0.9 \mathrm{M}$ and then centrifuged again. Collagen purification was performed by reimmersion in the acetic acid solution and then precipitated again with the procedures similar as before. The wet collagen obtained was then dried with a freeze drier to obtain dry collagen.

\section{Chitosan Membrane Fabrication from Barramundi Scales}

Preparation of chitosan solution was performed by immersing the chitosan with a concentration of $2 \%$ in $1 \%$ acetic acid. As much as $2 \mathrm{~g}$ of chitosan was immersed in $100 \mathrm{~mL}$ of acetic acid so that the chitosan produced would be in a gel form. Addition of collagen was performed by adding as much as $1 \mathrm{~g}$ of collagen in the chitosan solution and then placed in the petri dish according to the required thickness. Afterward, the solution mixture was being frozen with the freeze drier, so that the frozen molecular water molecules would be removed or drawn to form a gas. This process was called sublimation. This sublimation process will cause membranes fabricated having pores. The membranes were cut to a certain size and packaged in a plastic wrap (-Fig. 1), then sterilization process was performed using the gamma-ray irradiation at a dose of $25 \mathrm{kGy}$ for 1 to 3 hours, depends on the amount of sterilized material.

\section{Chitosan-Collagen Membrane Characterization FTIR Analyses}

FTIR is a tool for measuring the radiation absorption of infrared regions at various wavelengths. ${ }^{18}$ This test is used to identify functional groups or collagen-chitosan compounds. The membrane sample was placed on a disk printer and then vacuumed to remove the gas content. The printed disk was then entered to the FTIR tool, and measured at the wavelength of 400 to $4,000 \mathrm{~cm}^{-1}$.

\section{Scanning Electron Microscopy}

All samples were placed in a vacuum-the device used was the FEI Quanta FEG 650 SEM with 2,000 kV accelerating voltage. The photos taken were the surface and the cross sections of the membrane with magnifications of $100 \times$ and $500 \times$.

\section{Tensile Strength}

Determination of the mechanical properties was performed by cutting the membrane with a size of $40 \times 10 \mathrm{~mm}$. The cutting ends were connected to the test equipment, and 
the tensile load was calculated with $\mathrm{N}$ as the load unit. The membrane was then being pulled at a certain speed until it breaks. The amount of the membrane tensile load at the time of breaking was recorded. This test was performed with a universal testing machine.

\section{Results}

Collagen extraction from barramundi scales using the acetic acid was referred to the research conducted by Moyunga et al. ${ }^{10}$ The collagen membrane was fabricated from collagen derived from barramundi scales, which were combined with chitosan. The fabrication was performed at The National Nuclear Energy Agency of Indonesia, Jakarta office. Collagen from barramundi scales was fabricated into membranes by cutting into $1 \times 1 \mathrm{~cm}$ pieces and sterilized using radiation isotopes. The resulting membrane was then tested for various mechanical properties that were tensile strength and elongation at break, membrane porosity, membrane sterilization, and SEM.

The FTIR analysis result showed the typical peak of a chitosan-collagen membrane ( - Fig. 2) was at the absorption wavenumber of $3,453.9 \mathrm{~cm}^{-1}$ as a hydroxyl $(-\mathrm{OH})$ group and also as an $\mathrm{NH}_{2}$ group, while at the peak of absorption wavenumber of $2,900 \mathrm{~cm}^{-1}$ is $\mathrm{C}-\mathrm{H}$, on the absorption wavenumber of $1,581.9 \mathrm{~cm}^{-1}$ was- $\mathrm{NH}_{2}$ bending. The presence of $\mathrm{CH}-\mathrm{NH}_{2}$ group was shown in the absorption wavenumber of $1,150.3$ $\mathrm{cm}^{-1}$. On the absorption wavenumber band of $1050 \mathrm{~cm}^{-1}$, the-C-O-C-glycosidic chain was presented between the chitosan monomer. Collagen had the typical peak on the absorption wavenumber of $3,453.9 \mathrm{~cm}^{-1}$ that was the group of hydroxyl $(-\mathrm{OH})$ and an amide group. On the absorption wavenumber of $2,900 \mathrm{~cm}^{-1}$, the $\mathrm{C}-\mathrm{H}$ group was presented, and an amide group was presented at the absorption wavenumber of $1581.9 \mathrm{~cm}^{-1}$ (-Table $\mathbf{1}$ ).

Tensile strength is the maximum stress that a material can resist when stretched or pulled before the material breaks. Tensile strength and elongation (elasticity) of the membrane were measured in dry and wet conditions (-Table 2). The tensile strength of the membrane was $0.28 \mathrm{MPa}$ at the dry condition, and elongation at break was $8.53 \%$, while in the wet condition, the tensile strength was $0.12 \mathrm{MPa}$ and elongation at break was $25.6 \%$.

Porosity test is a measurement of spaces between the materials, and is a fraction of the volume of spaces to the total volume, expressed as the percentage between 0 and $100 \%$. The membrane porosity test result in this study was $38.85 \%$, which indicated that the spaces formed on the membrane were $\sim 38.85 \%$ of the total volume of the membrane.

In this study, membrane sterilization was performed using the $25 \mathrm{kGy}$ gamma irradiation rays, which resulted that until 14 days, there was no microbial growth in the thioglycolate medium (-Table 3). Sterilization at a dose of $25 \mathrm{kGy}$ was quite effective for sterilizing the membrane from microbial growth.

SEM is an electron microscope designed to observe the surface of a solid object directly. SEM focuses on an electron beam on the object's surface and captures its image by

Table 1 FTIR data of chitosan-collagen membrane

\begin{tabular}{|l|l|l|}
\hline $\begin{array}{l}\text { Wavenumber } \\
\left(\mathrm{cm}^{-1}\right)\end{array}$ & Chitosan & Collagen \\
\hline 3453.9 & $-\mathrm{NH}_{2}$ & $-\mathrm{OH}$ \\
\cline { 2 - 3 } & $-\mathrm{OH}$ & Amide \\
\hline 2900 & $\mathrm{C}-\mathrm{H}$ & $\mathrm{C}-\mathrm{H}$ \\
\hline 1581.9 & $\mathrm{NH}_{2}$ Bending & Amide \\
\cline { 2 - 3 } & $\begin{array}{l}\text { Primary } \\
\text { alcohol }\end{array}$ \\
\hline 1150.3 & $\begin{array}{l}\mathrm{CH}-\mathrm{NH}_{2} \\
-\mathrm{C}-\mathrm{O}-\mathrm{C} \\
\text { glycosidic }\end{array}$ \\
\hline 1050 & \\
\hline
\end{tabular}

Abbreviation: FTIR, Fourier transform infrared.

Table 2 The membrane tensile strength and elongation at break

\begin{tabular}{|l|l|l|}
\hline $\begin{array}{l}\text { Membrane } \\
\text { condition }\end{array}$ & $\begin{array}{l}\text { Tensile strength } \\
\text { (MPa) }\end{array}$ & $\begin{array}{l}\text { Elongation at } \\
\text { break (\%) }\end{array}$ \\
\hline Dry & 0.28 & 8.53 \\
\hline Wet & 0.12 & 25.6 \\
\hline
\end{tabular}

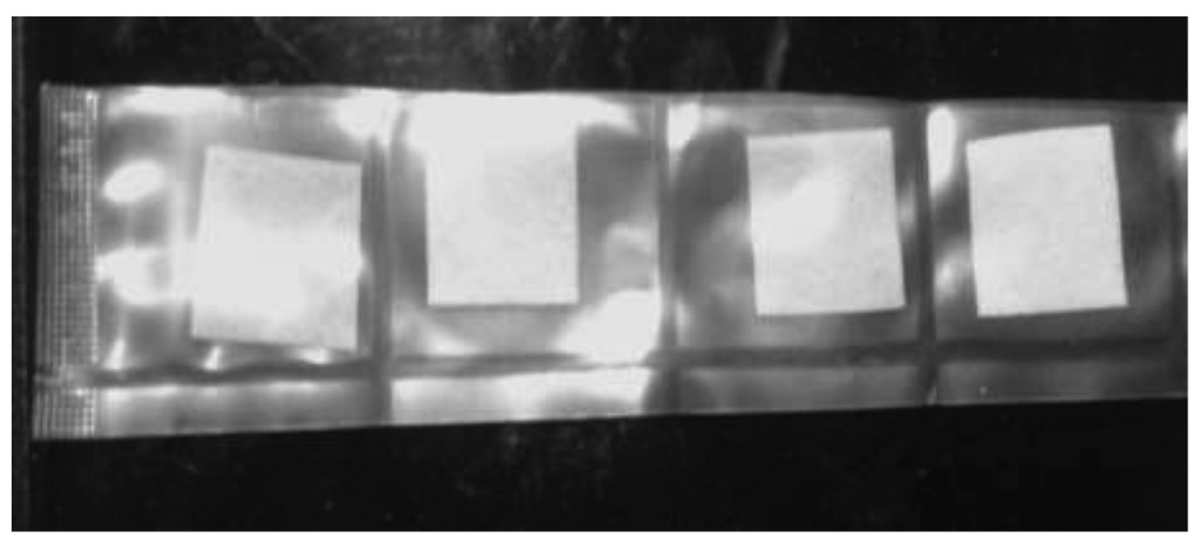

Fig. 1 Collagen membrane sized $1 \times 1 \mathrm{~cm}$, wrapped with sealed and sterilized plastic. 
detecting electron appearance from the object surface. The scanning result of the collagen membrane using the SEM showed that the collagen elements were able to fuse with other elements, which were the chitosan and the mixture was homogeneous. The membrane surface was porous with sizes varying around 16 to $100 \mu \mathrm{m}$ ( - Fig. 3 ).

\section{Discussion}

The results of this study concluded that the chitosan-collagen membrane from barramundi scale showed the fibrous membrane surface, interconnected porous and ideal porous size as GTR membrane, and the lower mechanical strength. The previous research of collagen barramundi scale was done by Krishnan et al ${ }^{19}$ and Sankar et al. ${ }^{12}$ Krishnan et al used a collagen of barramundi scale as a corneal tissue engineering material; this study concluded that collagen from barramundi scales has good mechanical and physicochemical characterization, and potential biomedical materials that can be used in treatment. ${ }^{19}$ Sankar et al stated that collagen from barramundi scales has good physical characteristics to

Table 3 Membrane sterility test

\begin{tabular}{|l|l|l|l|l|l|l|l|l|}
\hline & \multicolumn{7}{|l|}{$\begin{array}{l}\text { Microbes growth (days) } \\
\text { (thioglycollate medium) }\end{array}$} \\
\hline & 1 & 2 & 3 & 4 & 5 & 6 & 7 & 14 \\
\hline Control & + & + & + & + & + & + & + & + \\
\hline $\begin{array}{l}\text { Tested } \\
\text { membrane }\end{array}$ & - & - & - & - & - & - & - & - \\
\hline
\end{tabular}

be used as wound dressing material which has porous and fibrous in morphology as shown in SEM images. ${ }^{12}$

The success of an integration of two polymer components depends on the intermolecular interactions, which will result in an improved quality of the alloy mechanical properties. Tensile strength and elongation at break indicate the strength and elasticity of the membrane that are an important physical parameter in supporting the clinical application of the membrane. ${ }^{3}$ Based on the results of the tensile strength measurement as presented in $\mathbf{- T a b l e} \mathbf{2}$, the fabricated membrane tensile strength in dry condition was 0.28 and $0.12 \mathrm{MPa}$ in a wet condition. The membrane tensile strength was less than $1 \mathrm{MPa}$ because the main element of this membrane was purely natural materials with no use of other synthetic chemicals to improve its mechanical properties. When compared with some existing membrane in the market, the tensile strength is still lower. Bio-Gide (Geistlich Biomaterials, Baden-Baden, Germany) membrane shows that maximum tensile stress and maximum tensile strain are $4.8 \mathrm{MPa}$ and $46.8 \%$, respectively, while Collprotect (Botiss Biomaterial, Italy) membrane shows that maximum tensile stress and maximum tensile strain are $13.1 \mathrm{MPa}$ and $13.1 \%$, respectively. ${ }^{20}$

The mechanical strength and chemical stability of the collagen membrane can be increased chemically by the use of compounds such as aldehyde and glutaraldehyde, and physically by ultraviolet and gamma irradiation. ${ }^{3}$ The use of gamma irradiation is intended not only to modify the membrane physical properties but also to sterilize the membrane. ${ }^{21}$ Our study was using the $25 \mathrm{kGy}$ gamma irradiation to sterilize the collagen membrane. Gamma-ray irradiation can damage hydrogen bonds between those two macromolecules; the high doses are used to cause degradation of chitosan chains. Application of

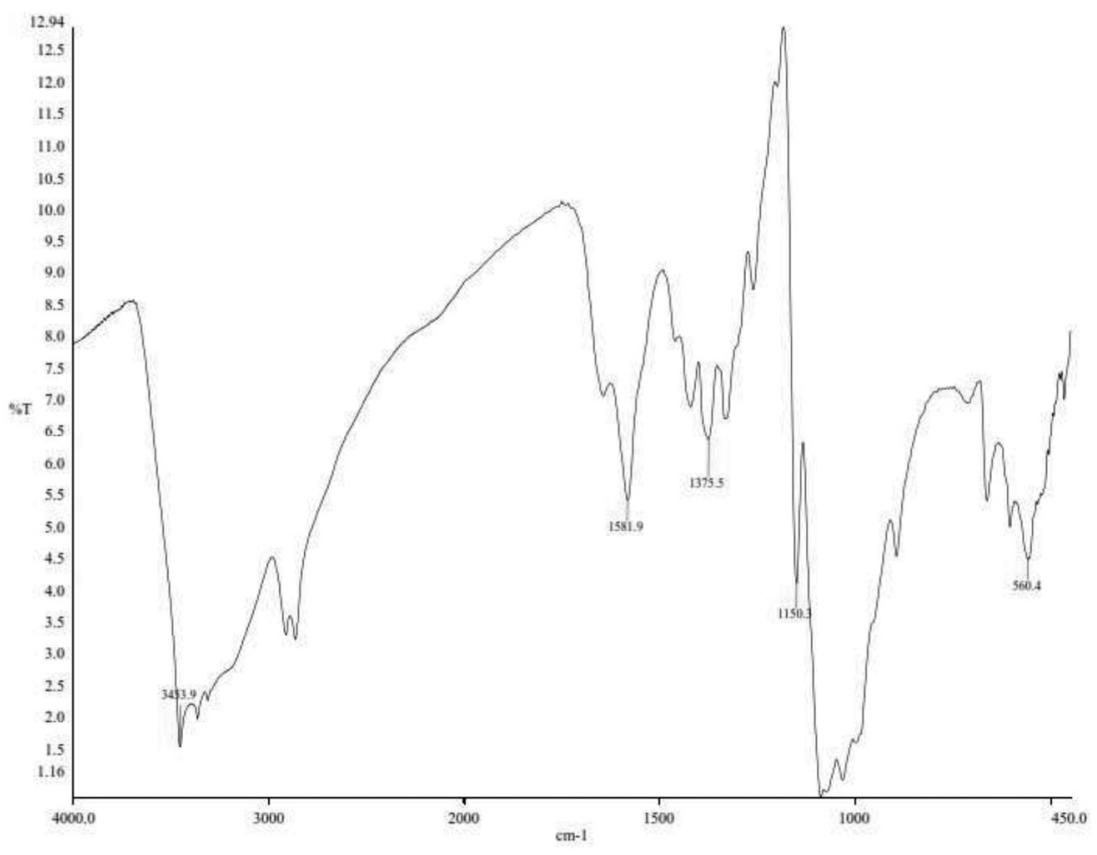

Fig. 2 Fourier transform infrared spectrum of chitosan-collagen membrane. 
gamma irradiation on a mixture of chitosan/collagen membranes can reduce tensile strength and extend breaking. ${ }^{22}$

Gamma radiation and electron beam are the most popular tools used for material sterilization in the health sector and food preservation. Both of these tools can be used to coat the material surface. The advantage of gamma radiation is the relatively fast process, no residue, no catalyst, or no initiator needed, and irradiation doses can be adjusted as required. ${ }^{22}$ In our study, gamma radiation is used to sterilize the fabricated membrane at a dose of $25 \mathrm{kGy}$. The membrane sterility test result is presented in - Table 3 and showed negative microbial growth until day 14 , in other words the use of gamma radiation was effective to sterilize the membrane.

The physical characteristics of the scaffold are an essential factor in tissue engineering. The three-dimensional scaffold structure becomes an extracellular matrix that is similar or analogous as a template and physical support to guide cell proliferation and differentiation. ${ }^{23}$ The three-dimensional scaffold must have high porosity and porous interconnected structures that will be able to facilitate cell attachment, proliferation, and differentiation. ${ }^{24,25}$ Based on the SEM analysis as shown in -Fig. 3, the elements of collagen and chitosan were mixed homogeneously, and the porous size of the membrane surface was approximately 16 to $100 \mu \mathrm{m}$. The porous size in our study was similar to the previous study conducted by Mighri et al ${ }^{26}$ and Rajam et al. ${ }^{28}$ Research by Mighri et al showed that the mixture of collagen and chitosan was able to show a homogeneous surface in the porous size and distribution. The study also stated that the size and porous distribution of the nonchitosan-coated collagen membrane and the chitosan-coated collagen membrane showed a varied surface. ${ }^{26}$ The porous size of the nonchitosan-coated membrane was higher (30-100 $\mu \mathrm{m})$ compared with the chitosan-coated membrane (30-70 $\mu \mathrm{m}){ }_{.}{ }^{27}$ The result of another study conducted by Rajam et al showed that the membrane or scaffold of collagen and chitosan had interconnected porous with an average diameter of 75 to $150 \mu \mathrm{m} .{ }^{28}$ The membranes showed a porous microarchitecture and some possibility of interconnectivity providing space for vascularization (-Fig.3). It has been reported that the minimum recommended pore size for a scaffold is $100 \mu \mathrm{m}$ to achieve adequate vascularization of the tissue/organ being repaired or regenerated.,29
Porous scaffold structure is influenced by the freezedrying method. During the freezing process, ice grain will be formed. The process of removing the crystals is performed by lyophilization so that the porous membrane will be created. ${ }^{22,24}$ Membrane surface with interconnected porous will be able to facilitate cell attachment, proliferation, and differentiation that play essential roles in the wound healing and tissue regeneration. Natural ingredients such as collagen and chitosan are more widely used in clinical applications because of their roles in facilitating cell attachment and growth, and also tissue regeneration. ${ }^{26}$

Management and treatment of bone defects are a major clinical problem in the field of periodontology and oral implantology. ${ }^{30}$ The final goal of periodontal therapy is to eliminate the inflammation and achieve periodontal tissue regeneration. ${ }^{31}$ The mechanisms of GTR/GBR are to isolate periodontal bone defects from gingival connective tissue so that the new bone growth will be formed along with the alveolar bone defect. ${ }^{32,33}$ Barrier membrane with a favorable function has to meet certain important design criterion that is biocompatibility. It should not stimulate the immune system or produce sensitization that may interfere with the wound healing process. To inhibit the migration of unwanted cells toward the material, the membrane should act as a barrier. This barrier, however, would allow the passage of nutrients and gases. Another important property of barrier material is tissue integration. This property inhibits a rapid epithelial migration on the material outer surface or material encapsulation. Ability to create and maintain a space adjacent to the root surface is another essential property. This property allows the cells from the periodontal ligament to entering the space. The membrane should have a design that is easy to trim and adjust to the desired site. Easy manipulation may affect the predictability of the clinical outcome. ${ }^{34}$

\section{Conclusion}

Within the limitations of this study, it can be concluded that chitosan-collagen membranes showed a fibrous membrane surface, ideal porous size recommended as GTR membrane; although it shows lower mechanical strength, this membrane
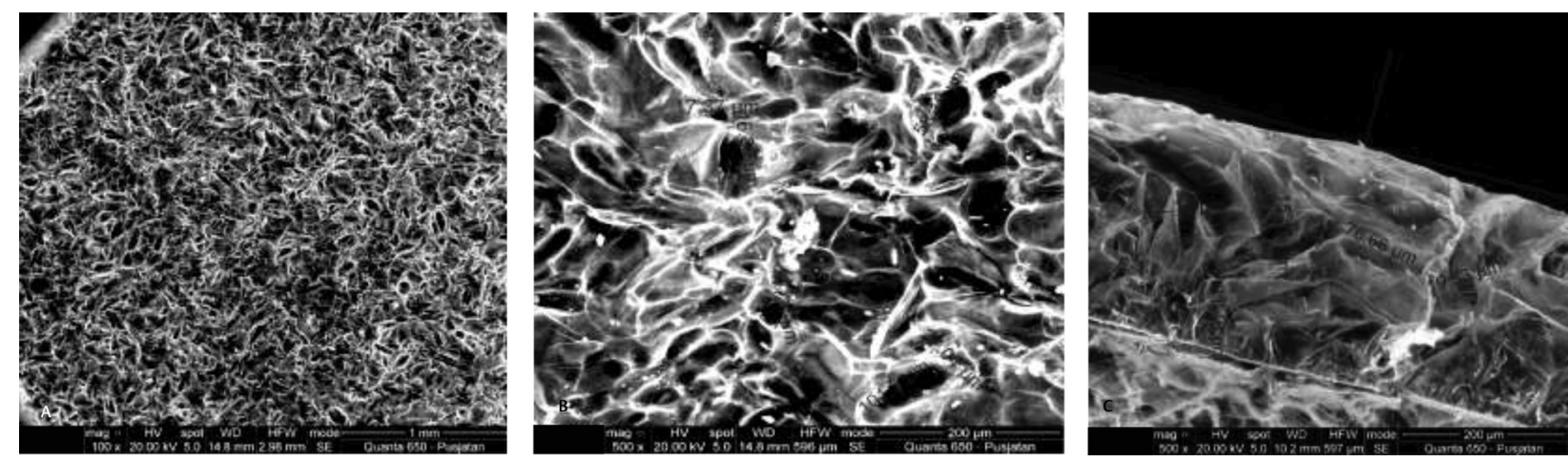

Fig. 3 Scanning electron microscope (SEM) result of collagen membrane with magnification 100x (A) and 500x (B); well-observed the homogeneity and porosity of the membrane surface. (C) SEM result of cross-sectional cut of collagen membrane with magnification of 500x, well-observed the fibrous and interconnected porous of membrane surface. 
has the potential to develop as an alternative membrane barrier for GTR. Further research is awaited to improve the mechanical strength of chitosan-collagen membranes.

\section{Funding}

None.

\section{Conflict of Interest}

None declared.

\section{References}

1 Pandit N, Malik R, Philips D. Tissue engineering: a new vista in periodontal regeneration. J Indian Soc Periodontol 2011;15(4):328-337

2 Zafar MS, Khurshid Z, Almas K. Oral tissue engineering progress and challenges. J Tissue Eng Regen Med 2015;12(6):387-397

3 Ferreira AM, Gentile P, Chiono V, Ciardelli G. Collagen for bone tissue regeneration. Acta Biomater 2012;8(9):3191-3200

4 Hughes FJ, Ghuman M, Talal A. Periodontal regeneration: a challenge for the tissue engineer? Proc Inst Mech Eng $\mathrm{H}$ 2010;224(12):1345-1358

5 Qasim SB, Delaine-Smith RM, Fey T, Rawlinson A, Rehman IU. Freeze gelated porous membranes for periodontal tissue regeneration. Acta Biomater 2015;23:317-328

6 Kielty CM, Hopkinson I, Grant ME, The collagen family: structure, assembly, and organization in the extracellular matrix. In: Royce PM, Steinmann B, eds. Connective Tissue and Its Heritable Disorders. New York: Wiley-Liss, Inc; 2002:159-221

7 Jongjareonrak A, Benjakul S, Visessanguan W, Nagai T, Tanaka M. Isolation and characterization of acid and pepsin-solubilized collagens from the skin of Brownstripe red snapper (Lutjanus vitta) . Food Chem 2005;93:475-484

8 Kittiphattanabawon P, Benjakul S, Visessanguan W, Nagai T, Tanaka M. Characterisation of acid-soluble collagen from skin and bone of bigeye snapper (Priacanthus tayenus) Food Chem 2005;89(3):363-372

9 Nagai T, Suzuki N. Isolation of collagen from fish waste material-skin, bone and fins. Food Chem 2000;68(3):277-281

10 Moyunga JH, Cole CGB, Duodu KG. Characterization of acid soluble collagen from skin of young and adult Nile perch (Lates niloticus). Food Chem 2004;85(1):81-89

11 Zhang Y, Liu W, Li G, Shi B, Miao Y, Wu X. Isolation and partial characterization of pepsin-soluble collagen from the skin of grass carp (Ctenopharyngodon idella). Food Chem 2007;103(3):906-912

12 Sankar S, Sekar S, Mohan R, Rani S, Sundaraseelan J, Sastry TP. Preparation and partial characterization of collagen sheet from fish (Lates calcarifer) scales. Int J Biol Macromol 2008;42(1):6-9

13 Anand S, Kamath S, Chuang L, Kasapis S, Lopata AL. Biochemical and thermo-mechanical analysis of collagen from the skin of Asian Sea bass (Lates calcarifer) and Australasian Snapper (Pagrus auratus), an alternative for mammalian collagen. Eur Food Res Technol 2013;236(5):873-882

14 Qasim SB, Husain S, Huang Y, et al. In-vitro and in-vivo degradation studies of freeze gelated porous chitosan composite scaffolds for tissue engineering applications. Polym Degrad Stabil 2017;136:31-38

15 Qasim SB, Najeeb S, Delaine-Smith RM. Rawlinson A, Ur Rehman I. Potential of electrospun chitosan fibers as a surface layer in functionally graded GTR membrane for periodontal regeneration. Dent Mater 2017;33(1):71-83

16 Jayakumar R, Prabaharan M, Nair SV, Tamura H. Novel chitin and chitosan nanofibers in biomedical applications. Biotechnol Adv 2010;28(1):142-150
17 Xu C, Lei C, Meng L, Wang C, Song Y. Chitosan as a barrier membrane material in periodontal tissue regeneration. J Biomed Mater Res B Appl Biomater 2012;100(5):1435-1443

18 Al Shehadat S, Gorduysus MO, Abdul Hamid SS, Abdullah NA, Samsudin AR, Ahmad A. Optimization of scanning electron microscope technique for amniotic membrane investigation: a preliminary study. Eur J Dent 2018;12(4):574-578

19 Krishnan S, Sekar S, Katheem MF, Krishnakumar S, Sastry TP. Fish scale collagen-a novel material for corneal tissue engineering. Artif Organs 2012;36(9):829-835

20 Ortolani E, Quadrini F, Bellisario D, Santo L, Polimeni A, Santarsiero A. Mechanical qualification of collagen membranes used in dentistry. Ann Ist Super Sanita 2015;51(3):229-235

21 Erizal E, Perkasa DP, Aziz Z, Sulistioso GS. Modification of physico chemical on polyvinyl alcohol chitosan composite membrane from casting process by gamma irradiation technique. Indonesian J Mater Sci 2013;14(3):166-172

22 Indrani DJ, Lukitowati F, Yulizar Y. Preparation of chitosan collagen blend membranes for wound dressing: a study on FTIR spectroscopy and mechanical properties. IOP Conference Series: Materials Science and Engineering 2017; 202(1):1-9

23 Deschamps IS, Magrin GL, Magini RS, Fredel MC, Benfatti CAM, M Souza JC. On the synthesis and characterization of. $\beta$. -tricalcium phosphate scaffolds coated with collagen or poly (D, L-lactic acid) for alveolar bone augmentation. Eur J Dent 2017;11(4):496-502

24 Archana D, Upadhyay L, Tewari RP, Dutta J, Huang YB, Dutta PK. Chitosan-pectin alginate as a novel scaffold for tissue engineering applications. Indian J Biotechnol 2013;12(4):475-482

25 Tangsadthakun C, Kanokpanont S, Sanchavanakit N, Banaprasert T, Damrongsakkul S. Properties of collagen/chitosan scaffold for skin tissue engineering. J Metal Mater Miner 2007;16(1):37-44

26 Mighri N, Mao J, Mighri F, Ajji A, Rouabhia M. Chitosan coated collagen membranes promote chondrocyte adhesion, growth, and interleukin-6 secretion. Materials (Basel) 2015;8(11):7673-7689

27 Pati F, Adhikari B, Dhara S. Isolation and characterization of fish scale collagen of higher thermal stability. Bioresour Technol 2010;101(10):3737-3742

28 Rajam AM, Jithendral P, Mandal AB, Rose C. Evaluation of in vitro macrophage response and in vivo host response to growth factors incorporated chitosan nanoparticle impregnated collagen-chitosan scaffold. J Biomed Nanotechnol 2014;10(3):508-518

29 Peter M, Binulal NS, Nair SV, Selvamurugan N, Tamura H, Jayakumar R. Novel biodegradable chitosan-gelatin/nanobioactive glass ceramic composite scaffolds for alveolar bone tissue engineering. Chem Eng J 2010;158(2):353-361

30 Song JM, Shin SH, Kim YD, et al. Comparative study of chitosan/ fibroin-hydroxyapatite and collagen membranes for guided bone regeneration in rat calvarial defects: micro-computed tomography analysis. Int J Oral Sci 2014;6(2):87-93

31 de Molon RS, Kim YJ, Dos Santos-Pinto A, Cirelli JA. Improvement of an anterior infrabone defect using combined periodontal and orthodontic therapy: a 6-year follow-up case report. Eur J Dent 2014;8(3):407-411

32 Karring T, Lindhe J, Cortellini P, Regenerative periodontal therapy. In: Lindhe J, Karring T, Lang NP, eds. Clinical Periodontology and Implant Dentistry. Munksgaard; New York: Blackwell Publishing Company; 2003:669-694

33 Moura CC, Soares PB, Carneiro KF, Souza MA, Magalhães D. Cytotoxicity of bovine and porcine collagen membranes in mononuclear cells. Braz Dent J 2012;23(1):39-44

34 Soheilifar S, Soheilifar S, Bidgoli M, Torkzaban P. Barrier membrane, a device for regeneration: properties and applications. Avicenna J Dent Res 2014;6(2):e21343 